\title{
TORSIONAL STRENGTHENING OF UNDER REINFORCED CONCRETE BEAMS USING CRIMPED STEEL FIBER
}

\author{
Likhil L. Raut ${ }^{1}$, D. B. Kulkarni \\ ${ }^{1} P G$ Student, M.Tech Civil Structure, Rajarambapu Institute of Technology, Islampur, Sangli, Maharashtra, India \\ ${ }^{2}$ Professor, Department of Civil Engineering, Rajarambapu Institute of Technology, Islampur, Sangli, Maharashtra, \\ India
}

\begin{abstract}
The paper deals with the experimental investigation of introduction of steel fibers in the normal reinforced concrete beams to enhance its torsional strength. Fibers are most generally discontinuous, randomly distributed throughout the concrete matrices. In present work study of Torsional behavior of Steel fiber reinforced concrete (SFRC) beams has been carried out over the normal reinforced concrete (NRC) beams. The torsional moment and angle of twist has been studied of steel fiber reinforced concrete and normal reinforced concrete beams under pure torsion. The fraction of fibers added in the concrete varies from $0 \%$ to $1 \%$ by volume of concrete, in the regular interval of $0.25 \%$. In this aspect ratio of steel fiber is kept as 38. For present research work, crimped shaped steel fibers having length $38 \mathrm{~mm}$ long are used. The casting of beams has done with the use of M 20 grade of concrete. Beam section was designed as singly reinforced under reinforced section. All beam specimens has been tested under two point loading until failure of beam for torsion on Universal Testing Machine.
\end{abstract}

Keywords: Steel fiber, reinforced concrete, beam, torsional strength

****

\section{INTRODUCTION}

Concrete is a composite material which is commonly used for activities of construction purpose. Concrete is also a relatively brittle material that performs significantly well in compression, but is considerably less effective in tension and its tensile strength is only approximately one tenth of the compressive strength. Tensile stresses are induced in concrete due to its shrinkage in both plastic and hardened stage resulting the cracking of concrete. Historically, steel reinforcement is used to absorb these tensile stresses and to prevent the cracking to some extent. The addition of steel reinforcement significantly increases the strength of concrete but to produce concrete with homogeneous tensile properties the micro cracks develops in concrete should be suppress.

The introduction of fibers was brought in a solution to develop concrete in the view of enhancing its flexural and torsional strength. Fibers are most generally discontinuous and having random distribution over the cement matrices. The term of "Fiber reinforced concrete" (FRC) is made up with cement, various sizes of aggregates along with discrete and discontinuous fibers. The concept of using fibers to improve the properties of construction materials is very old. Historically, horsehair was used in mortar and straw in mud bricks. In the early 1900's asbestos fibers were used in concrete. By the 1960's steel, glass, synthetic and natural fibers are also used in concrete and now a day's many types of fibers are available for use in concrete [1].

The real advantage of adding fibers is that, after matrix cracking, fibers bridge these cracks and restrict them. In case of further deflection of the beam, additional forces and more energy is required to pull out or fracture the fibers.
This process, apart from preserving the integrity of concrete, improves the load-carrying capacity beyond cracking [1]. Purpose of using steel fibers is to control cracks at different size levels in different zones of concrete, stress levels and to enhance the properties of concrete by combining the benefits of that fiber can impart. In this paper experimental study on torsional behaviour of steel fiber reinforced concrete has carried out.

\subsection{Torsional Strengthening of Beams}

Early efforts for understanding the response of plain concrete subjected to pure torsion revealed that the material fails in tension rather than shear. Structural members curved in plan, members of a space frame, eccentrically loaded beams, curved box girders in bridges, spandrel beams in buildings, and spiral stair-cases are typical examples of the structural elements subjected to torsional moments and torsion cannot be neglected while designing such members. The different shapes of structural element subjected to torsion are such as T, inverted L, I-shapes and box sections. These different shapes of structures make the understanding of torsion in RC members a complex task.

In addition, torsion is usually associated with bending moments and shearing forces, the interaction between these forces is important. Thus, behaviour of concrete members in torsion is primarily governed by the tensile response of the material, particularly its tensile cracking characteristics. Spandrel beams, located at the perimeter of buildings, carry loads from slabs and beams from one side of the member only. Such loading conditions generate the torsional forces that are transferred from the spandrel beams to the columns. Reinforced concrete (RC) beams have been found to be 
deficient in torsional capacity and in need of strengthening. These kinds of deficiencies occur due to several reasons, such as lesser area provided of stirrups than required resulting from construction errors or inadequate design, reduction in the required area of steel due to corrosion. In the case of torsion, all sides of the member are subjected to diagonal tension. Similar to the flexure and shear strengthening, the FRC (Fiber Reinforced Concrete) also helps RC (Reinforced Concrete) members for torsion strengthening.

\subsection{Fiber Reinforced Concrete}

Fiber reinforced concrete is defined as a composite material consisting of mixtures of cement, mortar or concrete and discontinues discrete, uniformly dispersed suitable fibers. The fiber is a small piece of reinforcing material possessing certain characteristics properties. They are circular or flat. The fiber is often described by the parameter aspect ratio which is ratio of fiber length to its diameter. Typical aspect ratio varies from 20 to 150 .

The use of fibers to reinforce a brittle material was done first by Egyptians they used straw to reinforce sun baked bricks and horsehair was used to reinforce plaster. In the early 1900 's asbestos fibers were used in concrete. The modern development of steel fiber reinforced concrete may have begun in 1960's. Glass fibers comes into picture by the 1980's and Carbon fibers from 1990's and now a day's many types of fibers are available as a construction material and among them consumption of steel and synthetic fibers are large.

\subsection{Types of Fibers}

Depending upon the parent material used for manufacturing fibers can be broadly classified as;

1. Metallic fibers (e.g. low carbon steel, stainless steel, galvanized iron, aluminum)

2. Mineral fibers (carbon, glass, asbestos etc.)

3. Synthetic fibers (polypropylene, polyethylene, polyester, nylon etc.)

4. Natural fibers (bamboo, coir, jute, sisal, wood, sugarcane bagasse etc.)

\subsection{Steel Fibers}

Steel fiber prevents the shrinkage cracks developed during hydration, making the structure strong and durable. Further, when the loads imposed on concrete approach that of failure cracks will propagate, sometimes rapidly. Addition of steel to concrete arrests cracking caused by volume change (expansion and contraction), simply because $1 \mathrm{~kg}$ of steel offers millions of fibres which support concrete in all directions.

A structure free from micro cracks prevents migration of water or moisture throughout the concrete. Hence this helps to prevent the corrosion of steel used for primary reinforcement of the structure. The modulus of elasticity of steel is high with respect to the modulus of elasticity of the concrete binder. Steel fibre helps in increasing flexural strength of concrete.

Table 1 Specification of Steel Fiber

\begin{tabular}{|l|l|l|l|}
\hline Cut Length & Shape & Diameter & Tensile Strength \\
\hline $38 \mathrm{~mm}$ & Crimped & $1 \mathrm{~mm}$ & $1000 \mathrm{MPa}$ \\
\hline
\end{tabular}

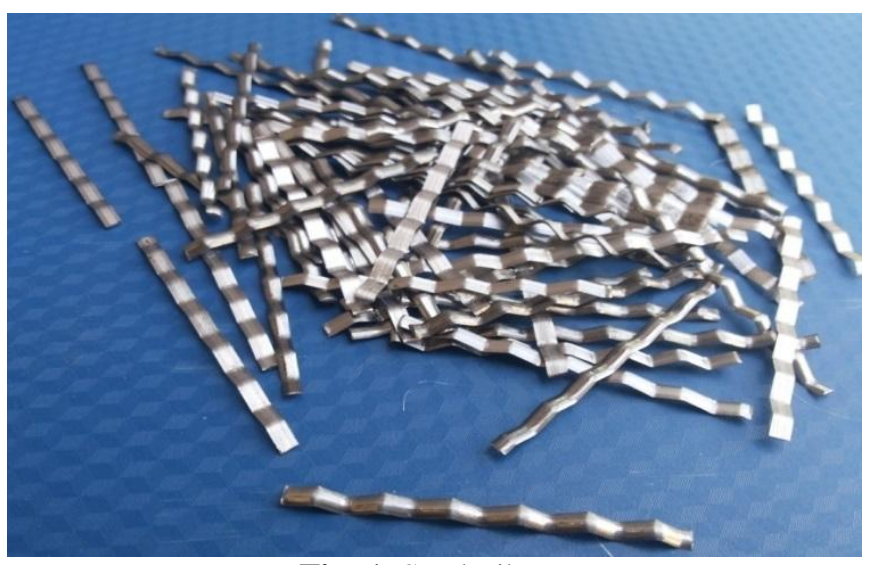

Fig -1: Steel Fibers

\section{EXPERIMENTAL PROGRAM}

The plain under-reinforced concrete (RC) beams as control beam and steel fiber reinforced concrete (RFRC) beams with varying percentage of fiber fractions were casted for experiment purpose. Steel fiber fraction added in the concrete matrix in the proportion of $0.25,0.50,0.75$ and $1 \%$ respectively to the volume of concrete. The dimensions of beam specimens were kept as $100 \mathrm{~mm}$ width $\times 150 \mathrm{~mm}$ depth and $1200 \mathrm{~mm}$ length. The two point loading was used to apply torsional loading on beams.

\subsection{Proportioning of Beam Specimen}

The flexural reinforcement consisted of two $8 \mathrm{~mm}$ diameter bars at the bottom and two $8 \mathrm{~mm}$ diameter bars at the top of the beam used as anchor bars. Shear reinforcement was provided in the form of two-legged rectangular stirrups with standard hooks. Stirrups were made of $6 \mathrm{~mm}$ diameter bars. The stirrups were $50 \mathrm{~mm}$ wide and $100 \mathrm{~mm}$ in depth. The center-to-center spacing of the stirrups was $140 \mathrm{~mm}$.

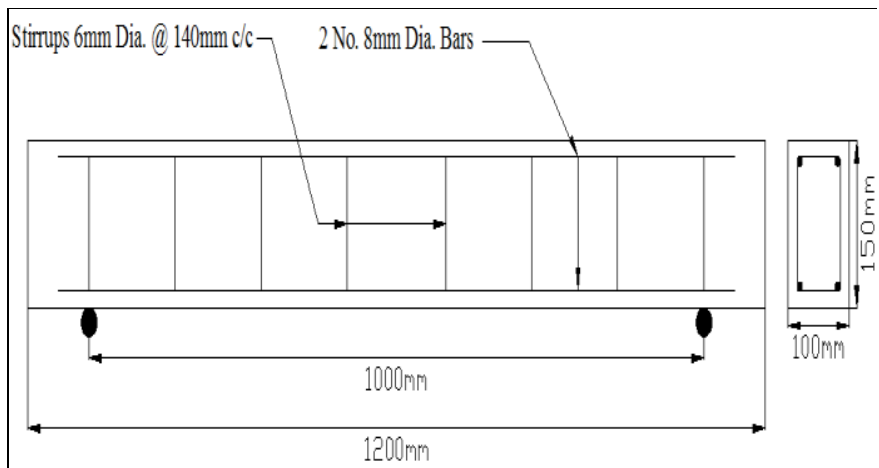

Fig -2: Reinforcement Details (Longitudinal Section \& Cross Section) 


\subsection{Materials}

The M 20 grade of concrete was used for the casting of RC and RFRC beams. An Ordinary Portland Cement (OPC) of $53 \mathrm{MPa}$ strength, locally available river sand as fine aggregate, crushed stone aggregate with a maximum particle size of $20 \mathrm{~mm}$ as coarse aggregate, Steel fibers and potable water were used in this investigation. The mix proportion obtained from these materials is given in table below;

Table 2 Mix Proportions for M 20

\begin{tabular}{|l|l|l|l|}
\hline Water & Cement & $\begin{array}{l}\text { Fine } \\
\text { Aggregate }\end{array}$ & $\begin{array}{l}\text { Coarse } \\
\text { Aggregate }\end{array}$ \\
\hline $186 \mathrm{~kg}$ & $372 \mathrm{~kg}$ & $637 \mathrm{~kg}$ & $1209 \mathrm{~kg}$ \\
\hline 0.50 & 1 & 1.71 & 3.25 \\
\hline
\end{tabular}

$\therefore$ Mix Proportion is $1: 1.71: 3.25$

\subsection{Designation of the Beams}

Table 3 Beam Casting Schedule

\begin{tabular}{|l|l|l|}
\hline Beam Type & Designation & $\begin{array}{l}\text { Fiber Fraction } \\
(\%)\end{array}$ \\
\hline Plain Concrete & Control Beam $(\mathrm{CB})$ & 0 \\
\hline Steel FRC & SFRC 1 & 0.25 \\
\hline Steel FRC & SFRC 2 & 0.50 \\
\hline Steel FRC & SFRC 3 & 0.75 \\
\hline Steel FRC & SFRC 4 & 1 \\
\hline
\end{tabular}

\subsection{Testing of Beams}

All the beams were tested for torsion under UTM of 60 Tonnes i.e. $600 \mathrm{kN}$ in the material lab of RIT engineering college Rajaramnagar. The three samples of each type of beam specimen were tested. All of them are tested in the torsional test arrangement as shown in fig. 3 and 4 . The gradual increase in load at every $0.5 \mathrm{kN}$ were observed for calculation of torsional moment and the deformation observed in the dial gauge with the least count of $0.01 \mathrm{~mm}$ for the calculation of angle of twist of beam. These increments in readings were taken throughout the test. The load was applied till the ultimate failure of beam. The deflections were taken at two end points of the beam, and the torsional moment by angle of twist graph was plotted from the obtained results.

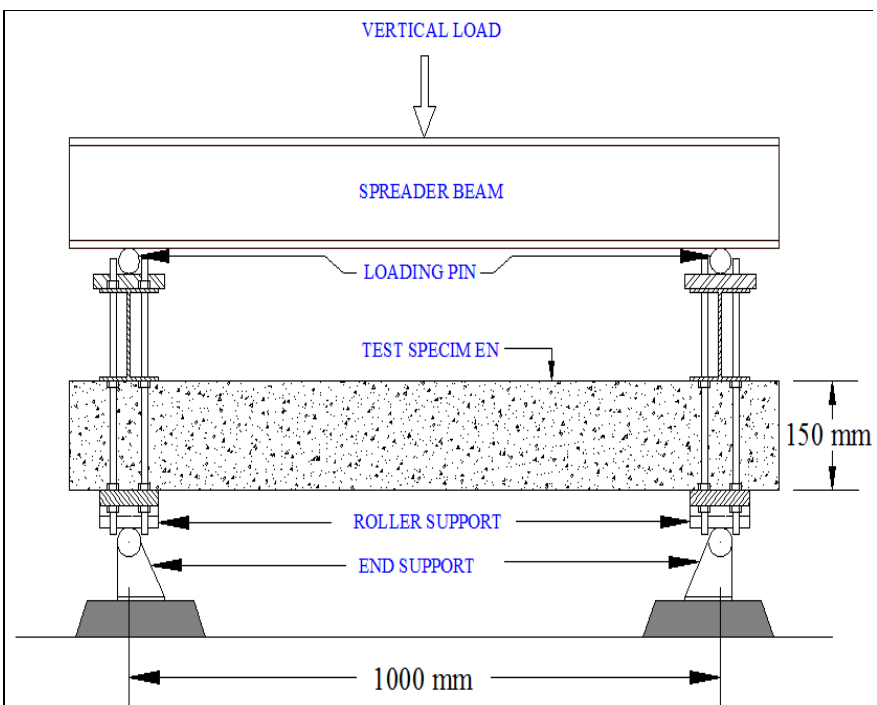

Fig -3: Schematic Test Setup

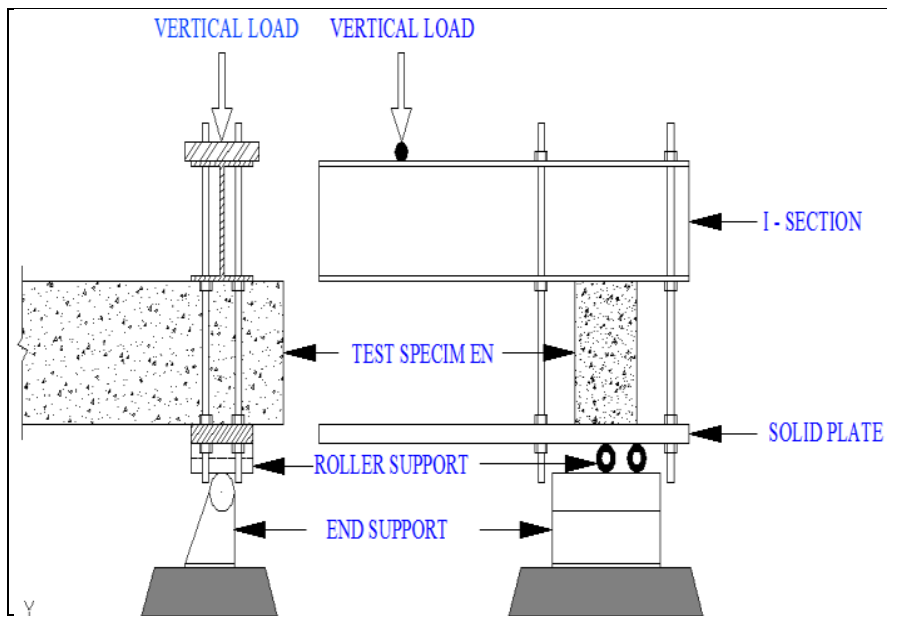

Fig -4: Schematic Test Setup at the End of Specimen

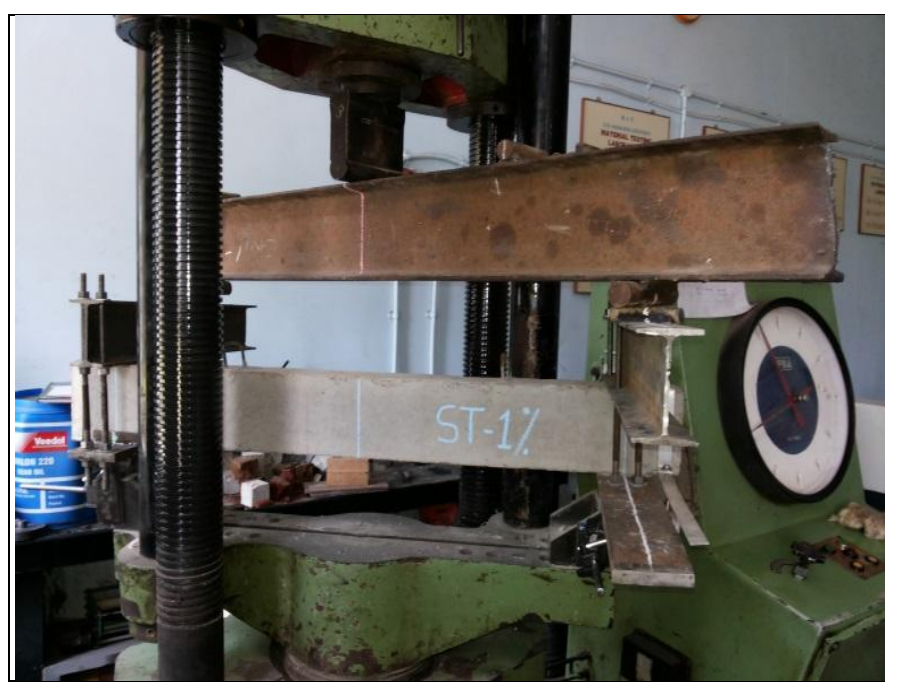

Fig -5: Experimental Setup of the Beam

\section{RESULTS AND DISCUSSION}

The final results obtained after calculations of all the test readings. 
Table 4 Test Results

\begin{tabular}{|l|l|l|l|}
\hline $\begin{array}{l}\text { Beam } \\
\text { Type }\end{array}$ & $\begin{array}{l}\text { Ultimate Load } \\
(\mathrm{kN})\end{array}$ & $\begin{array}{l}\text { Torsional } \\
\text { Moment } \\
(\mathrm{kNm})\end{array}$ & $\begin{array}{l}\text { Angle of } \\
\text { Twist } \\
(\mathrm{rad} / \mathrm{m})\end{array}$ \\
\hline CB & 5.50 & 1.826 & 0.03333 \\
\hline SFRC 1 & 5.70 & 1.892 & 0.0364 \\
\hline SFRC 2 & 6.75 & 2.241 & 0.0349 \\
\hline SFRC 3 & 8.10 & 2.689 & 0.0616 \\
\hline SFRC 4 & 7.05 & 2.341 & 0.0540 \\
\hline
\end{tabular}

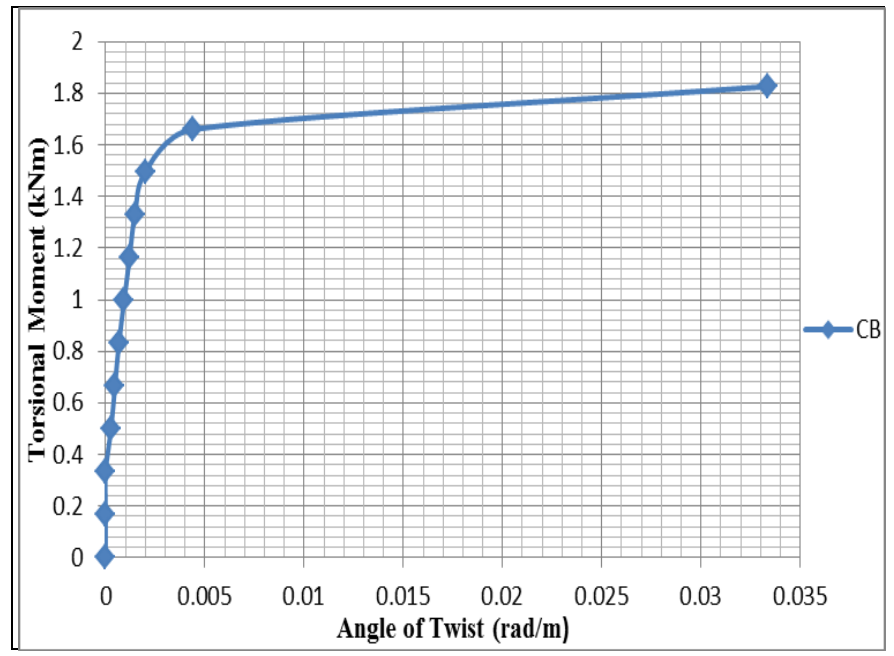

Chart -1: Torque Twist response of $\mathrm{CB}$

Chart -1 The control beam failed completely in torsion at a load of $5.5 \mathrm{kN}$ and torsional moment of $1.826 \mathrm{kNm}$. It was observed that cracks were appeared making an angle $40^{\circ}-50^{\circ}$ with the main beam. The cracks were developed in a spiral pattern all over the main beam which later leads to the failure of the beam in torsional shear.

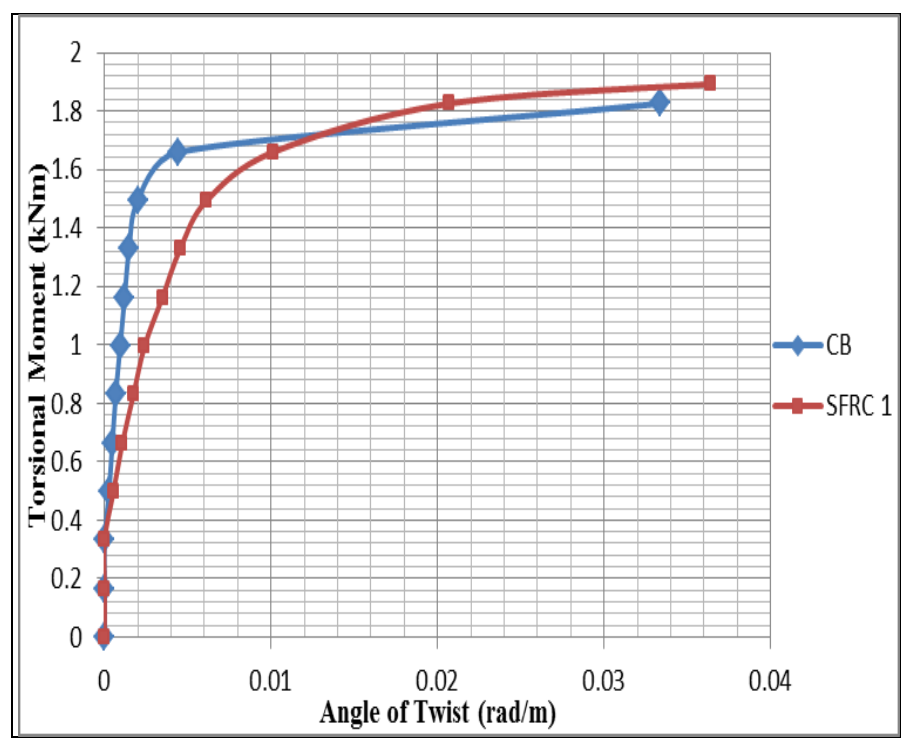

Chart -2: Torque Twist response of CB \& SFRC1
Chart -2 The beam failed completely in torsion at a load 5.7 $\mathrm{kN}$ and torsional moment $1.892 \mathrm{kNm}$. The increase in the strength of beam was $3.64 \%$ as compared to control beam.

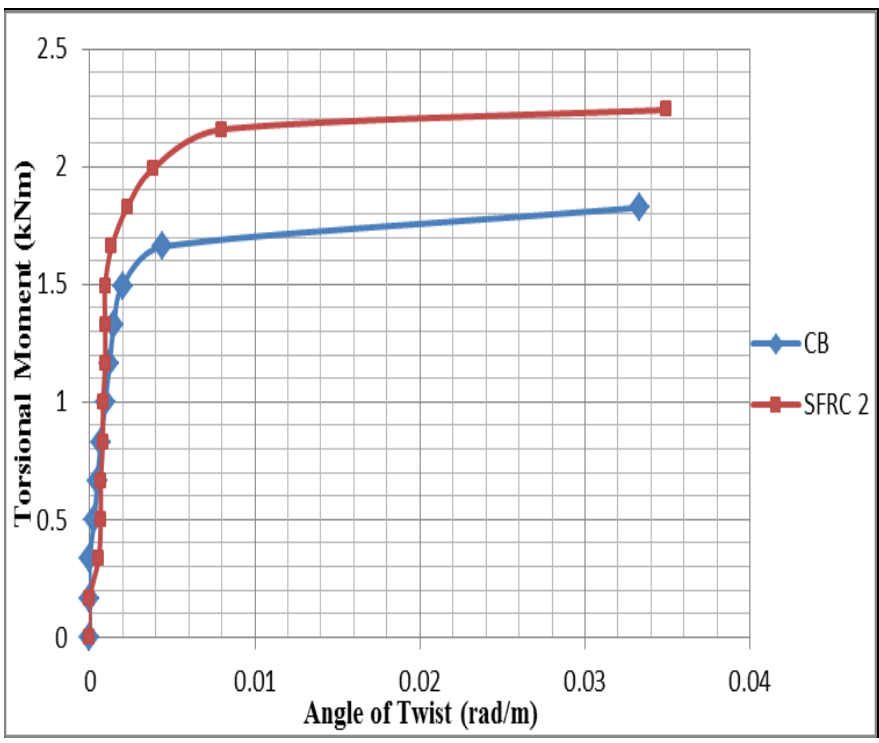

Chart -3: Torque Twist response of CB \& SFRC2

Chart -3 The beam failed completely in torsion at a load 6.75 $\mathrm{kN}$ and torsional moment $2.241 \mathrm{kNm}$. The increase in the strength of beam was $22.73 \%$ as compared to control beam.

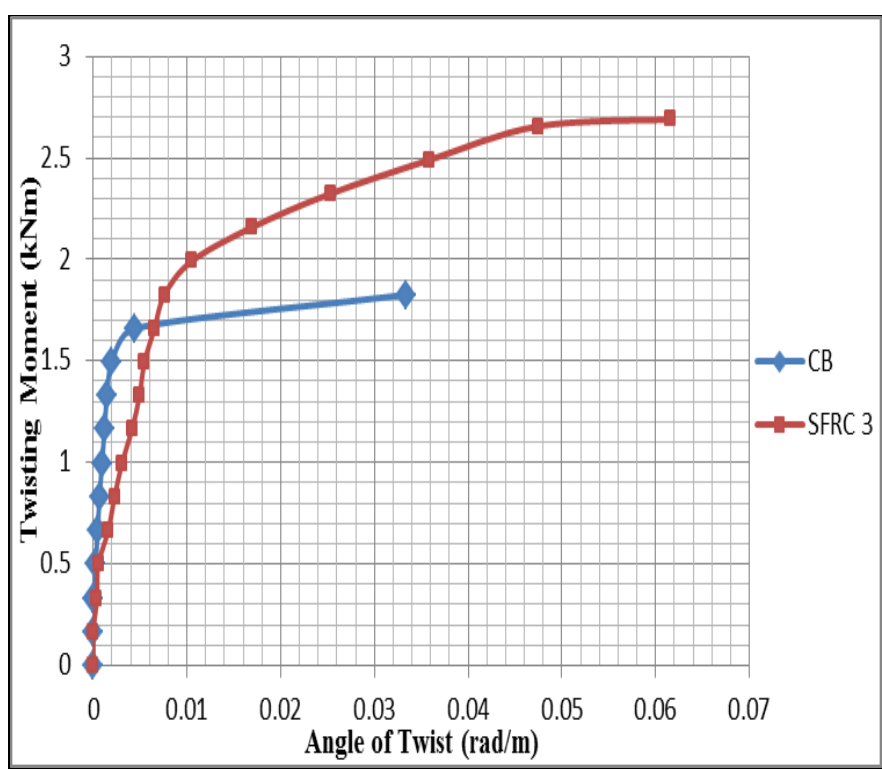

Chart -4: Torque Twist response of CB \& SFRC3

Chart -4 The beam failed completely in torsion at a load 8.10 $\mathrm{kN}$ and torsional moment $2.689 \mathrm{kNm}$. The increase in the strength of beam was $47.27 \%$ as compared to control beam. 


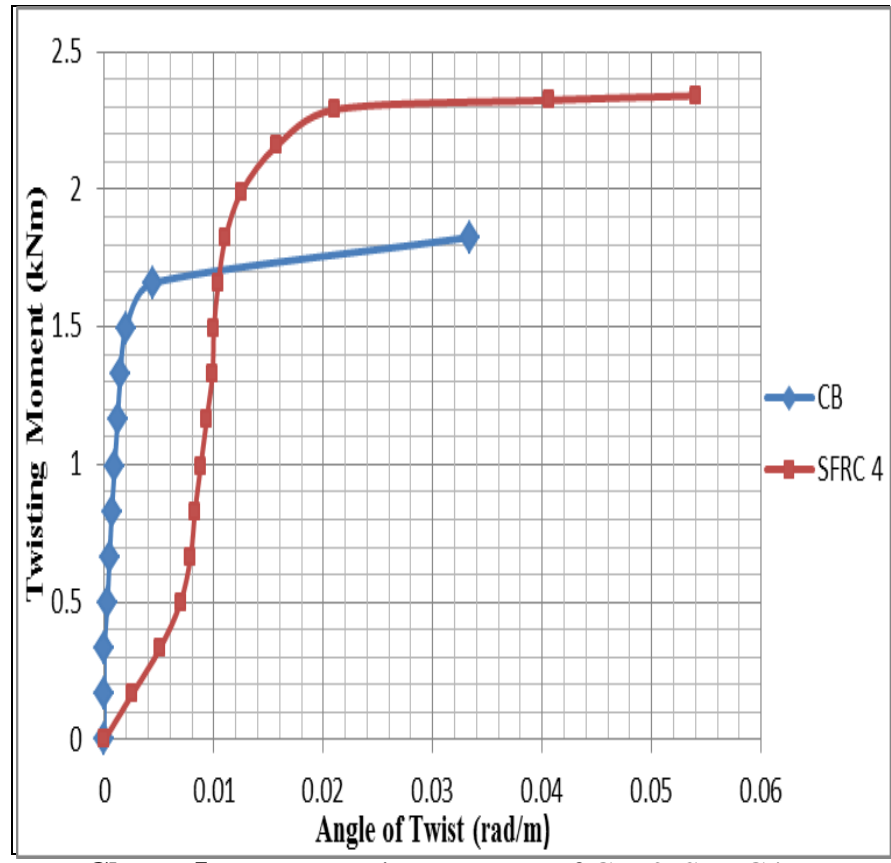

Chart -5: Torque Twist response of CB \& SFRC4

Chart -5 The beam failed completely in torsion at a load $7.05 \mathrm{kN}$ and torsional moment $2.341 \mathrm{kNm}$. The increase in the strength of beam was $28.18 \%$ as compared to control beam.

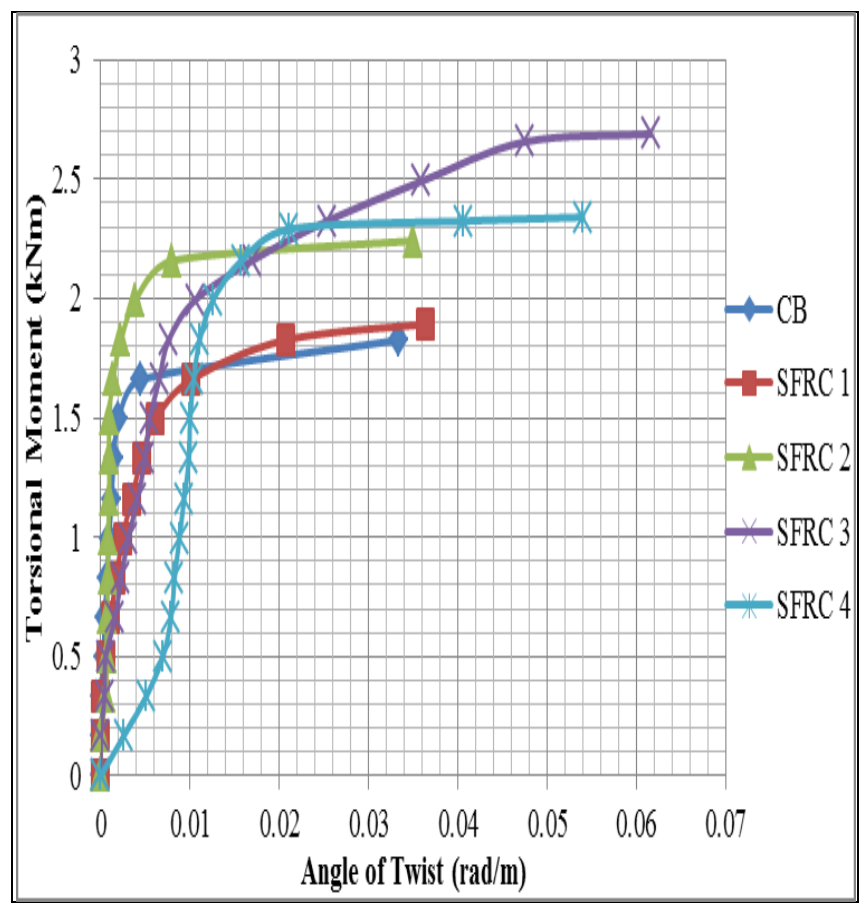

Chart -6: Torque Twist response of All Beams

Chart -6 It is clear that SFRC 3 beam which strengthen with $0.75 \%$ steel fiber fraction experienced largest value of torsional moment and angle of twist up to the failure of beam.

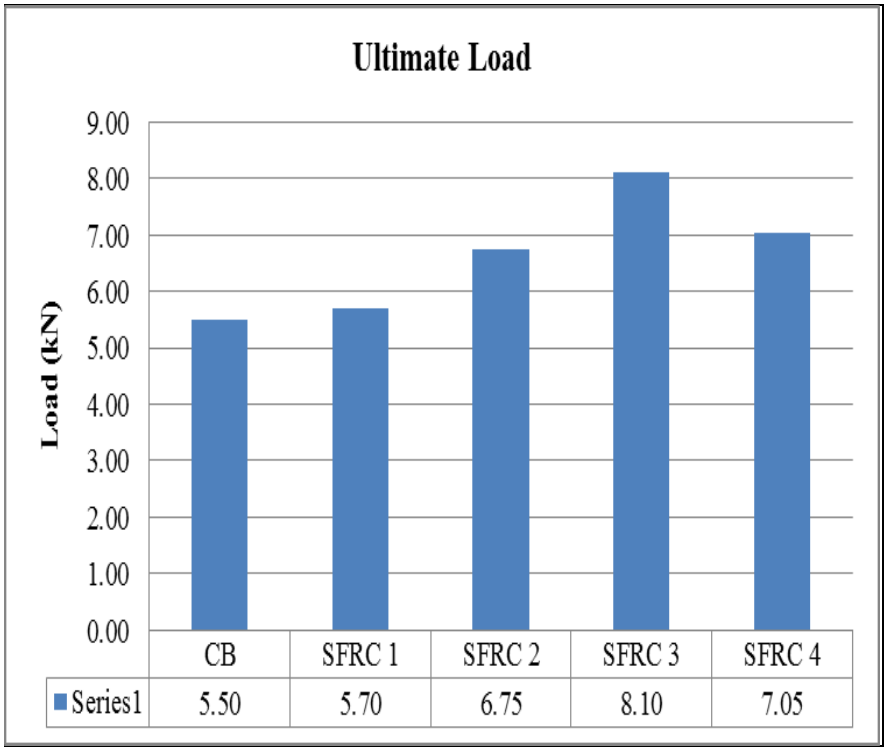

Chart -7: Variation of Ultimate Load

Chart -7 shows the load carrying capacity of the control beam and the SFRC strengthen beams. It was observed that SFRC 3 with fraction of $0.75 \%$ steel fiber beam having the max load carrying capacity.

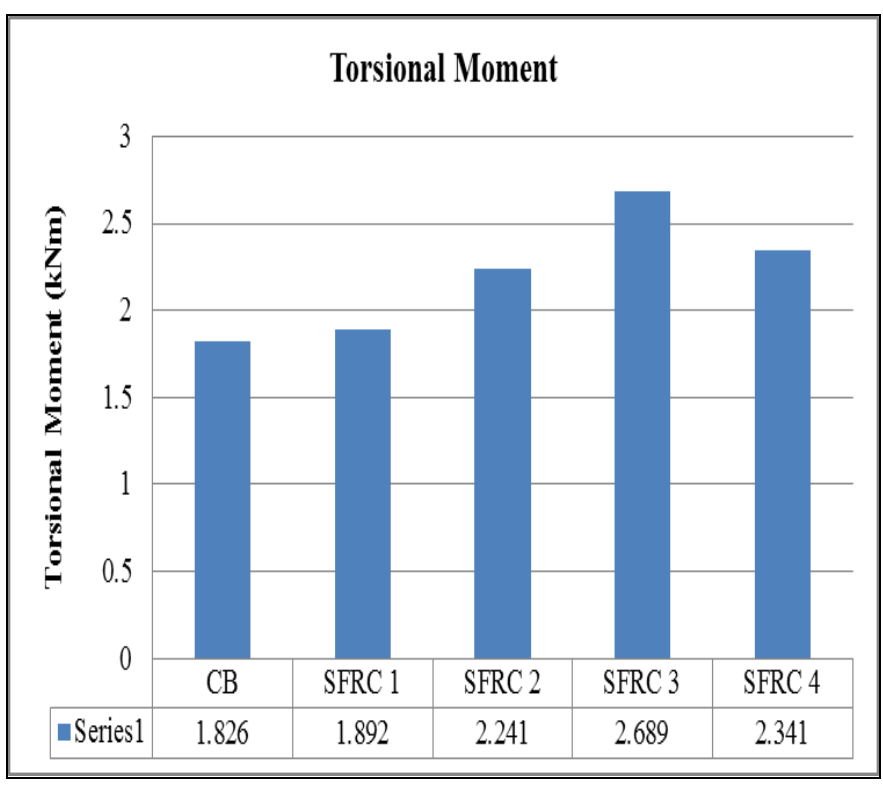

Chart -8: Variation of Torsional Moment

Chart -8 shows the torsional strength for steel fiber reinforced strengthened beam with respect to the control beam.

\section{CONCLUSIONS}

From the results obtained following conclusion is drawn;

- Use of fiber has found very beneficial to increase the torsional strength of $\mathrm{RC}$ beam subjected to pure torsion.

- The torsional strength of SFRC beams has increased up to $47.27 \%$ which is very significant increase in the strength of concrete compared to conventional RC Beam. 
- The fiber reinforcement has also succeeded to increase stiffness of the beam by decrease the angle of twist of strengthen beam compared to conventional RC beam.

- The initial crack pattern has observed at higher loads in the fiber reinforced strengthen beams.

- The $0.75 \%$ of steel fiber fraction gives the more comprehensive results in terms of strength and twisting angle over other percentage of fiber fractions.

\section{REFERENCES}

[1]. Sukontasukkul P. (2004). "Toughness evaluation of steel and polypropylene fibre reinforced concrete beams under bending", Thammasat Int. J. Tech., Vol. 9, Part 3, pp. 35-41.

[2]. Krishna Rao MV., Dakhshina Murthy NR., Santhosh Kumar V. (2011). "Behaviour of polypropylene fibre reinforced fly ash concrete deep beams in flexure and shear", Asian Journal of Civil Engineering (Building And Housing), Vol. 12, Part 2, pp. 143-154.

[3]. Sable K. S. and Rathi M. K. (2012). "Comparison of normal compacted concrete and self-compacted concrete in shear \& torsion", International Journal of Computer Technology and Electronics Engineering, Vol. 2, Part 4, pp. 74-79.

[4]. Rao G. and Seshu R. (2006). "Torsional response of fibrous reinforced concrete members: Effect of single type of reinforcement", Journal of Construction and Building Materials, Vol. 20, pp. 187-192.

[5]. Ramadevi K. and Venkatesh D. L. (2012). "Flexural Behavior of Hybrid (Steel-Polypropylene) Fibre Reinforced Concrete Beam", European Journal of Scientific Research, Vol. 70, Part 1, pp. 81-87.

[6]. IS 456:2000, Indian Standard Plain and Reinforced Concrete -code of practice (Fourth Revision).

\section{BIOGRAPHIES}

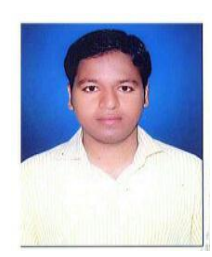

Mr. Likhil L. Raut, MTech Civil Structure, Rajarambapu Institute of Technology, Rajaramnagar, Sangli, India

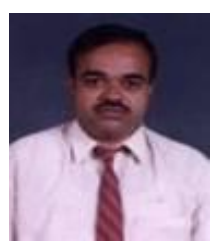

Prof. D. B. Kulkarni, Associate Professor, Rajarambapu Institute of Technology, Rajaramnagar, Sangli, India 